\title{
Robotic Transoral Thyroidectomy: Right Thyroidectomy and Ipsilateral Central Neck Dissection with da Vinci Si Surgical System
}

\author{
Hyo Ki Kim, M.D., Hong Kyu Kim, M.D., Ph.D., Dawon Park, M.D., Hoon Yub Kim, M.D., Ph.D., FACS \\ Department of Surgery, KUMC Thyroid Center, Korea University Hospital, Korea University College of Medicine, Seoul, Korea
}

\begin{abstract}
Transoral approach for thyroidectomy recently gains a lot of attention among the thyroid surgeons, with the merits of cosmetic outcomes and minimal flap dissection. We've successfully introduced the robotic surgical system to the transoral approach for thyroidectomy. For transoral robotic thyroidectomy, we made 3 incisions in the gingival-buccal sulcus for three intraoral ports. An additional axilla port was inserted for counter-traction and later drain insertion. Herein, our unique procedures of transoral robotic thyroidectomy (TORT) are described in the treatment of a patient with papillary thyroid carcinoma.
\end{abstract}

Keywords: Remote-access thyroidectomy, Robotic thyroidectomy, Transoral thyroidectomy

Supplementary video file: This article contains supplementary material (https://doi.org/10.7602/ jmis.2019.22.1.43).

This is an Open Access article distributed under the terms of the Creative Commons Attribution Non-Commercial License (http:// creativecommons.org/licenses/by-nc/4.0/) which permits unrestricted non-commercial use, distribution, and reproduction in any medium, provided the original work is properly cited.
Received October 4, 2018

Revised October 24, 2018

Accepted October 29, 2018

Corresponding author

Hoon Yub Kim

Department of Surgery, Korea

University College of Medicine, 73

Inchon-ro, Seongbuk-gu, Seoul

02841, Korea

Tel: $+82-2-920-6849$

Fax: +82-2-928-1631

E-mail: hoonyubkim@gmail.com ORCID:

http://orcid.org/0000-0002-6731-3912

Copyright $\odot 2019$ The Journal of Minimally Invasive Surgery. All rights reserved.

\section{INTRODUCTION}

With the introduction of endoscopic surgical instrument, transoral approach became available in thyroidectomy. After the first human transoral thyroidectomy study by Wihelm, et al., endoscopic transoral approach in thyroidectomy has been modified and improved throughout, from TOVANS (TransOral Video-Assisted Neck Surgery) and TOPOT (Trans-Oral Periosteal Thyroidectomy) to TOETVA (Trans-Oral Endoscopic Thyroidectomy Vestibular Approach) nowadays. ${ }^{1-4}$

Endoscopic transoral thyroidectomy has gained great popularity among many countries for its satisfactory cosmetic and surgical outcome. After the introduction of TOPOT, we went further to apply robotic surgery with transoral approach in thyroidectomy and came out with the Trans-Oral Robotic Thyroidectomy (TORT) method. ${ }^{5,6}$ In this study, we describe our unique TORT techniques and show its safety and feasibility.

\section{OPERATIVE PROCEDURE}

\section{Patient}

A 46-year-old female patient who was diagnosed as right PTC underwent TORT and ipsilateral central neck dissection using the da Vinci $\mathrm{Si}^{\oplus}$ surgical system (Sunnyvale, CA, USA). This surgery was approved by the Institutional Review Board of Korea University Hospital (No. 2017AN0077). The patient 
was counseled on the various approaches for thyroid surgery used in our institution, including conventional transcervical, bilateral axillo-breast, and transoral approaches.

\section{Working space formation}

\section{Patient positioning and draping}

The patient was positioned supine and intubated with an electromyogram tube (Medtronic, Minneapolis, MN, USA). After general anesthesia was induced draping was performed to expose her upper chest, bilateral axillae, and lower lip. Subsequently, her oral cavity was irrigated with a solution of chlorhexidine and povidone-iodine.

\section{Incision and flap}

Diluted epinephrine $(1: 200,000)$ was injected at the flap area in the subplatysmal space using a 22-gauge spinal tap needle, then three incisions were made in the gingival-buccal sulcus: one inverted U-shaped 2-cm midline incision approximately 2 $\mathrm{cm}$ above the frenulum labii inferioris, and two $0.5-\mathrm{cm}$ lateral incisions near the angle of mouth (Fig. 1). Once an adequate flap was created using a vascular tunneler, $12 \mathrm{~mm}$ bariatric Excel trocar and two $5 \mathrm{~mm}$ short robot trocars were inserted through the incisions. An additional $8 \mathrm{~mm}$ robot bariatric trocar was inserted through an incision made along the right axillary fold for counter-traction and subsequent insertion of the closed-suction drain.

\section{Docking stage}

Patients were placed in the lithotomy position with the $\mathrm{Si}$ system, and the robot was docked on the midline between the

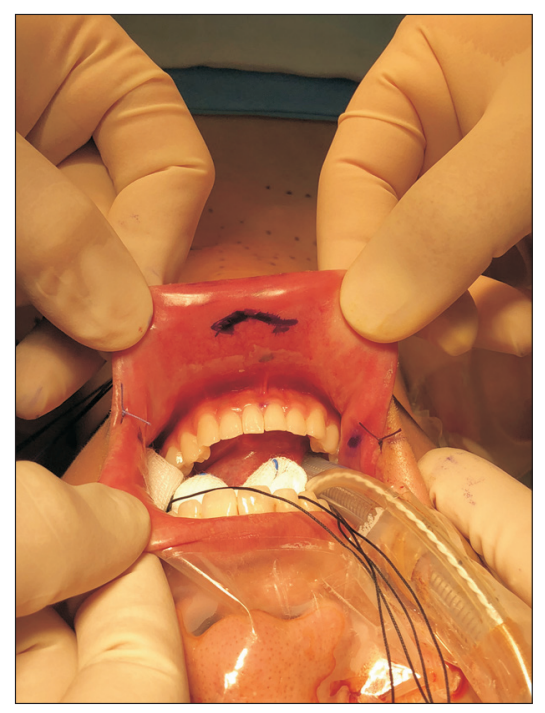

Fig. 1. Intraoral incision sites. patient's legs (Fig. 2). A 12-mm camera were used through the intraoral middle port for operative viewing. Harmonic $\mathrm{ACE}+$ curved shears (Ethicon Endo-Surgery, Cincinnati, $\mathrm{OH}$, USA), a needle driver, and monopolar hook cautery through the intraoral right lateral port were used for dissection and coagulation. A 5-mm Maryland dissector was used for thyroid manipulation. For counter-traction, 8-mm PreCise ${ }^{\mathrm{TM}}$ bipolar forceps were docked to the right axillary port.

\section{Console stage}

The isthmus was divided in the midline and the posterior surface of the isthmus was detached from the trachea to the ligament of Berry. Next, the avascular plane between the upper pole of the thyroid and the cricothyroid muscle was developed and the upper pole vessels were divided individually using ultrasonic energy device. The superior parathyroid was then identified and dissected downward, with caution. To identify the recurrent laryngeal nerve (RLN), the thyroid gland was retracted upward and a meticulous dissection performed around the site of insertion. Intraoperative nerve monitoring (NIM-response 3.0 $0^{\circledR}$, Medtronic, Minneapolis, MN, USA), was routinely used to confirm the location and integrity of the RLN. A prophylactic unilateral central neck dissection was performed and the specimens were removed by using an endoplastic bag. A Jackson-Pratt drain was placed through the axillary port.

\section{RESULTS}

A 46-year-old female patient was found to have $0.8 \mathrm{~cm}$ sized right thyroid nodule. The cytologic result of fine needle

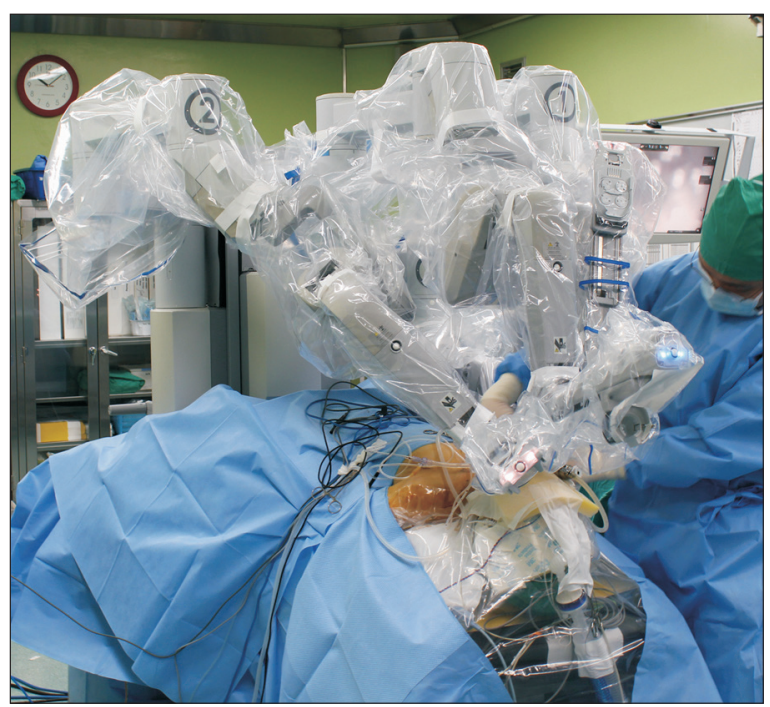

Fig. 2. Docking of the robotic system. 
aspiration was suspicious for papillary carcinoma (Bethesda V). The patient underwent TORT and ipsilateral central neck dissection. There was no event in the postoperative recovery period, and she was discharged on the second day after the operation without any complications. The final pathology demonstrated $0.8 \mathrm{~cm}$ sized papillary carcinoma with metastasis in 0 out of 6 regional lymph nodes, with a final staging of pTlaNOM0 (AJCC 8th edition).

\section{DISCUSSION}

One of the most outstanding merits of TORT is that transoral thyroidectomy shows excellent cosmetic outcome by utilizing natural orifice for its access - intraoral scars are not only hidden from the exterior but also can be completely disappeared in a few months. ${ }^{5,6}$ Furthermore, because the access point of the instruments are very close to the operative field, the flap dissection required for surgery has been much reduced compared to the previous robotic thyroidectomy methods. Cephalo-caudal and midline access allows surgeons to have easier access to the central neck dissection field as well.

TORT also carries several distinctions in technical aspects compare to TOETVA. Robotic multi-articulating instrumentations and the additional axillar robotic arm for countertraction of upper strap muscle allows TORT to have deeper approach into the superior pole for complete dissection. In addition, TORT has flexible counter-traction around peri-neural tissue near the RLN and the trachea which allows complete dissection of ligament of Berry as well as radial central neck dissection. ${ }^{5,6}$

In comparison with previous surgical approaches, transoral thyroidectomy has been associated with the potential possibil- ity of serious infection complications since oral microflora can be exposed into the neck exploration plain. Yet, animal experiments demonstrated no infection after the transoral thyroidectomy, and so far, with the proper usage of prophylactic IV antibiotics and the wound drain, no patient has experienced postoperative infection after TORT. Some other minor TORTspecific complications from earlier time - mental nerve injury, zygomatic region bruise, oral commissure tearing, etc. - have been overcome via fine refinement and modification of surgical details along with careful monitoring of the robotic arm movement range by the assistant.

\section{REFERENCES}

1) Wilhelm T, Metzig A. Endoscopic minimally invasive thyroidectomy (eMIT): a prospective proof-of-concept study in humans. World J Surg 2011;35:543-551.

2) Nakajo A, Arima H, Hirata M, et al. Trans-Oral Video-Assisted Neck Surgery (TOVANS). A new transoral technique of endoscopic thyroidectomy with gasless premandible approach. Surg Endosc 2013;27:1105-1110.

3) Lee HY, You JY, Woo SU, et al. Transoral periosteal thyroidectomy: cadaver to human. Surg Endosc 2015;29:898-904.

4) Anuwong A. Transoral Endoscopic Thyroidectomy Vestibular Approach: A Series of the First 60 Human Cases. World J Surg 2016;40:491-497.

5) Kim HY, Chai YJ, Dionigi G, Anuwong A, Richmon JD. Transoral robotic thyroidectomy: lessons learned from an initial consecutive series of 24 patients. Surg Endosc 2018;32:688-694.

6) Chai YJ, Kim HY, Kim HK, et al. Comparative analysis of 2 robotic thyroidectomy procedures: Transoral versus bilateral axillobreast approach. Head Neck 2018;40:886-892. 